\title{
Tam Buğday Ekmeğine Uygulanan Isıl İşlemin Ekmeğin Glisemik İndeksi Üzerine Etkisi
}

\author{
Impact of Heat Treatment on the Glycemic Index of Whole Wheat Bread
}

\author{
Aslıhan Özkan ${ }^{1}$, Duygu Sağlam²
}

Geliş tarihi/Received: 26.10.2017 • Kabul tarihi/Accepted: 03.04.2018

\section{ÖZET}

Amaç: Ekmek ülkemizde temel karbonhidrat ve enerji kaynaklarındandır. Obezite, diyabet ve kalp hastalıklarının önlenmesi ya da tedavisinde besin ögesi içeriği nedeni ile tam buğday unundan ekmek tüketimi önerilmektedir. Buna karşın literatürde ekmeğe uygulanan ısıtma işleminin glisemik indeks üzerine etkisinin gösterildiği çalışmalar sınırlı sayıdadır. Bu çalışmanın amacı tam buğday ekmeğine uygulanan ısıl işlemin glisemik indeks üzerine etkisini saptamaktır.

Bireyler ve Yöntem: Çalışma 19-35 yaş arası (22.5×3.4 yıl, 6 erkek, 4 kadın) 10 sağlıklı birey ile yürütülmüştür. Bireylere birer hafta ara ile 8 saatlik açlık sonrası 50 g sindirilebilir karbonhidrat içeren referans besin olarak glukoz ve beyaz ekmek, test besini olarak tam buğday ekmeği ile 6 dakika boyunca $220^{\circ} \mathrm{C}$ ısıl işlem uygulanmış tam buğday ekmeği verilmiş ve 0 , 15 , 30, 45, 60, 90. ve 120. dakikalarda parmak ucundan kapiller kan glukoz ölçümleri aynı cihazla yapılmıştır.

Bulgular: Çalışma sonucunda glukoza göre tam buğday ekmeğinin glisemik indeksi 78.4 iken, ısıl işlem uygulanmış tam buğday ekmeğinin 107.7 bulunmuştur. Tam buğday ve kızarmış tam buğday ekmeğinin 0, 15, 30, 60. ve 90. dakikalarda kan glukoz düzeyini yükseltme miktarları arasında istatistiksel olarak önemli bir fark bulunmazken (p>0.05), 45. ve 120. dakikalarda anlamlı farklılık gözlenmektedir $(\mathrm{p}<0.05)$.

Sonuç: Bu çalışmanın sonucuna göre tam buğday ekmeğine uygulanan ısıl işlemin glisemik indeksi yükselttiği saptanmıştır. Glisemik indeksin obezite ve kronik hastalıklarla ilişkisi olduğundan glisemik indeksi arttıracak pişirme tekniklerinden uzak durulması önemlidir.

Anahtar kelimeler: Ekmek, glisemik indeks, ısıl işlem

\section{ABSTRACT}

Aim: In Turkey, bread is a major source of carbohydrates and energy. Whole wheat bread is recommended based on the evidence of its effects on prevention and treatment of obesity, diabetes and heart diseases. In our knowledge, there is not any study demonstrating the effect of heating methods on glycemic index of whole wheat bread. The aim of this study was to determine the effect of heating on the glycemic index of whole wheat bread.

Subjects and Methods: All subjects consumed 50 g digestable carbohydrate from glucose, white bread (reference food), whole wheat bread, whole wheat bread toasted in oven for 6 minutes at $220^{\circ} \mathrm{C}$ (test foods) after 8 hours of fasting in weekly intervals. Capillary blood glucose measurements of the subjects were made on $0,15,30,45,60,90$, and $120^{\text {th }}$ minutes.

Result: Compared to glucose, glycemic index values were 78.4 for whole wheat bread; 107.7 for toasted whole wheat bread. While there was no significant difference between blood glucose levels in whole wheat bread and toasted whole wheat bread

1. İletişim/Correspondence: Gevye Devlet Hastanesi, Sakarya, Türkiye - E-posta: aslihan.ozkan@outlook.com

(D) https://orcid.org/0000-0002-4722-0110
2. Beslenme ve Diyetetik Bölümü, Acıbadem Mehmet Ali Aydınlar Üniversitesi, İstanbul, Türkiye (D) https://orcid.org/0000-0002-2993-4072 
at $0 ., 15 ., 30 ., 60$. and $90^{\text {th }}$ minutes ( $p>0.05$ ), statistically significant differences in $45^{\text {th }}$ and $120^{\text {th }}$ minutes were determined $(\mathrm{p}<0.05)$.

Conclusion: According to the results of the study, heat treatment of whole wheat bread for 6 minutes at $220^{\circ} \mathrm{C}$ raises glycemic index. Since the glycemic indexes of foods are associated with the risk of obesity and chronic diseases, cooking methods that increases glycemic index should be avoided.

Keywords: Bread, glycemic index, heat treating

\section{GİRIŞ}

Karbonhidrat içeren besinlerin postprandiyal glukoz yanıtını belirlemek için glisemik indeks kavramı kullanılmaktadır (1). Glisemik indeks (Gİ) besin ve besin karbonhidrat oranının sabit kaldığı 50 gram karbonhidrat içeren test besinin aynı bireyde, o bireyin kan glukoz yanıt eğrisi değerlendirilerek oluşturulan ve bu eğride artan bölgenin altında kalan alanın yüzdeyle ifade edildiği bir değerdir (2). Beyaz ekmek veya glukoz, diğer besinlerin Gí'inin belirlenmesinde referans olarak kullanılmaktadır. Sinıflandırma yapılırken kullanılan referans besinin Gİ değeri 100 kabul edilir ve test edilen besinin Gİ değeri bu referans besine göre hesaplanır (2). Besinler glisemik indeks değerlerine göre düşük, orta ve yüksek olarak değerlendirilmektedir. Hesaplanan glisemik indeks 55 ve altında ise düşük, 55 ile 70 arasında ise orta, 70 ve üzeri ise yüksek olarak sınıflandırılmaktadır (3). Tüm karbonhidrat türleri kan glukozu üzerinde aynı etkiyi göstermezler. Son 10 yıl içerisinde glisemik indeksin öğün sonrası glukoz metabolizması, insülin direnci, kardiyovasküler hastalık (KVH) ve kronik hastalık risk etmenleri üzerine etkisi ile ilgili birçok önemli epidemiyolojik ve deneysel çalışma yayınlanmıştır (4-8).

Ekmek, buğday ununa su, tuz, maya (Saccharomyces cerevisiae) gerektiğinde şeker, enzimler, enzim kaynağı olarak malt unu, vital gluten ve izin verilen katkı maddeleri eklenip bu karışımın tekniğine uygun olarak yoğrulması, şekillendirilmesi, fermentasyona bırakılması ve pişirilmesi ile yapılan üründür (9). Türk mutfağının temel besin ve karbonhidrat kaynağı olması nedeni ile ülkemizde ekmek tüketimi yaygındır. Türkiye Beslenme ve Sağlık Araştırması 2010 verilerine göre ülkemizde beyaz ekmek türlerinin \%85.4 oranında her gün tüketildiği, bu oranın kırsal bölgelerde kentlere göre daha yüksek olduğu saptanmıştır (sırasıyla \%88.8 ve \%84.3). Tam tahıl ekmeklerini tüketmeyenlerin oranının kentte yaşayanlarda \%68.1, kırda yaşayanlarda ise \%81.0 olduğu ifade edilmektedir. Kentte yaşayan kadınların \%22.7'si, erkeklerin \%13.6'sı her gün tam tahıllı ekmek tüketmektedir. Kırda yaşayanlarda ise tam tahıllı ekmek tüketim oranı \%10.5 olup her iki cinsiyette benzer oranlardadir (10).

Yapılan çalışmalar obezite ile karbonhidratın glisemik yapısı arasındaki ilişkiyi desteklemektedir $(11,12)$. Sindirim ve emilimlerinin yavaş olması sayesinde düşük glisemik indeksli besinler tokluğu arttırarak, sonraki öğündeki besin alımını azaltırlar. Bunun tersine yüksek glisemik indeksli besinler iştahı uyararak, yüksek enerji alımına neden olur (13).

Glisemik indeksin diyabet gelişimine etksinin değerlendirildiği kısa süreli bir insan çalışmasında, yüksek glisemik indeksli beslenmenin diyabet gelişimine katkı sağlayabileceği gösterilirken, uzun dönem çalışmalar glisemik indeks ve tip 2 diyabet riski arasındaki ilişkiyi tanımlamada yetersiz kalmaktadır (14). Hemşirelerin Sağlığı Çalışması I (15) ve Sağlık Profesyonelleri Takip Çalışması'nda (16) yüksek glisemik indeks ve artmış yük diyabet için risk olarak ifade edilirken, Iowa Kadın Sağlığı Çalışması'nda herhangi bir ilişki saptanamamıştır (17).

Besinlerin glisemik olarak oluşturduğu yanıt, insülin yanıtını da doğrudan etkilemektedir. Karbonhidrat içeren besinlerin glisemik cevabını belirlemede besinlerle ilgili birçok etmen bulunmaktadır. 
Dolayısı ile aynı miktardaki farklı öğün bileşimleri veya farklı besinler farklı glisemik ve insülinemik yanıtlar oluşturabilmektedir. Besinlerin saklama koşulları, pişirme süresi ve pişirme tekniği glisemik indeksi etkileyebilmektedir (18). Farklı pişirme ve saklama çeşitlerinin ekmeğin glisemik indeks etkisine yönelik yapılan bir çalışmada ev yapımı beyaz ekmek ve ticari beyaz ekmeğin dört farklı depolama ve hazırlık koşullarıyla elde edilen taze, dondurulmuş ve çözdürülmüş, kızartılmış, kızartılıp ardından dondurulup ve çözdürülen ekmeklerin glisemik yanıtı üzerine etkisine bakılmıştır. Taze ev yapımı beyaz ekmek ile dondurulmuş ve çözdürülmüş, kızartılmış, kızartılıp ardından dondurulup çözdürülmüş ekmekler karşılaştırıldığında taze beyaz ekmek tüketimi sonucu oluşan kan glukoz düzeyi diğerlerine göre anlamlı ölçüde düşük bulunmuştur ( $p<0.05)$. Benzer şekilde ticari beyaz ekmek için de aynı sonuç elde edilmiştir. Bu çalışma buzdolabında bekletilen ekmeklerde oluşan ekmeğin retrogradasyonu sonucu glisemik indeksinde artış olduğunu göstermektedir (19). Ekmeğin kuru ısıya maruziyeti sonucunda nişastada bulunan amiloz ve amilopektin yapı daha küçük ünitelere parçalanarak dekstrinleri oluşturur. Kızarmış ekmekte hissedilen tatlı tadın nedeni bu dekstrinizasyon olayından kaynaklanmaktadır. Ticari kahvaltılık gevreklerde hissedilen tatlı tadın nedeni de bu süreçtir (20). Bu çalışmanın amacı tam buğday ekmeğine uygulanan ısıl işlemin ekmeğin glisemik indeksi üzerine etkisini saptamaktır.

\section{BİREYLER VE YÖNTEM}

Araştırma Acıbadem Üniversitesi’nde öğrenim gören ve araştırmaya katılmayı kabul eden, 19-35 yaş arası

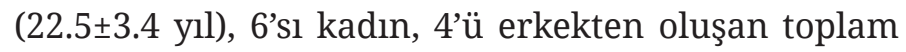
10 sağlıklı birey ile yürütülmüştür. Tanısı konmuş herhangi bir kronik veya endokrin hastalığı bulunan, BKİ $\geq 30 \mathrm{~kg} / \mathrm{m}^{2}$ olan, metabolizmayı etkileyen ilaçları düzenli olarak kullananlar, herhangi bir nedenle diyet yapmak zorunda olan bireyler çalışma dışı bırakılmıştır. Çalışmaya katılmayı kabul eden bireylere "Hasta Onam Formu" okunarak, onayları alınmıştır.

Çalışma 24.11.2016 tarihli ATADEK-2016/19 sayılı Acıbadem Üniversitesi Tıbbi Araştırmalar Değerlendirme Kurulu (ATADEK) izni ile uygun bulunmuştur.

Bireylerin sağlıklı olma durumları, Haydarpaşa Numune Eğitim ve Araştırma Hastanesi'nde dâhiliye uzmanı hekim tarafından on iki saatlik açlık sonrasında alınan kan örneklerinde değerlendirilen glukoz, insülin, glikozillenmiş hemoglobin (HbA1c), alanin amino transferaz (ALT), aspartat aminotransferaz (AST), trigliserit, total kolesterol, yüksek dansiteli lipoprotein (HDL)-kolesterol, düşük dansiteli lipoprotein (LDL)-kolesterol parametreleri ile belirlenmiştir. Biyokimyasal kan parametrelerinin değerlendirilmesindeki amaç, bireylerin araştırmaya uygunluğunun değerlendirilmesidir. Araştırmadaki tüm katılımcıların çalışma öncesi antropometrik ölçümleri (boy uzunluğu ve vücut ağırlığı) alınmıştır. Bireylerden elde edilen verilerden vücut ağırlığı ve boy uzunluğu kullanılarak beden kütle indeksi (BKİ) hesaplanmıştır.

\section{Araştırma Protokolü}

Tam buğday ekmeği ile ısıl işleme maruz kalan tam buğday ekmeğinin glisemik indeksinin belirlenmesinde glukoz ve beyaz ekmek referans besin olarak kullanılmıştır. Çalışmanın birinci aşamasında beyaz ekmek ile test edilecek besinler

Tablo 1. Referans ve test besinlerinin nem, yağ, protein, posa, karbonhidrat ve kül miktarları

\begin{tabular}{lccccccc}
\hline Ekmek türü & $\begin{array}{c}\text { Nem } \\
(\mathbf{\% )}\end{array}$ & $\begin{array}{c}\text { Yağ } \\
\mathbf{( \% )}\end{array}$ & $\begin{array}{c}\text { Protein } \\
\mathbf{( \% )}\end{array}$ & $\begin{array}{c}\text { Posa } \\
\mathbf{( \% )}\end{array}$ & $\begin{array}{c}\text { Sindirilebilir } \\
\text { karbonhidrat } \\
\text { (\%) }\end{array}$ & $\begin{array}{c}\text { Kül } \\
\text { (\%) }\end{array}$ & $\begin{array}{c}\text { Verilen ekmek } \\
\text { miktarı } \\
\text { (g) }\end{array}$ \\
\hline Beyaz ekmek & 34.0 & 0.5 & 9.10 & 0.3 & 54.7 & 1.4 & 91.4 \\
Tam buğday ekmeği & 36.9 & 1.98 & 8.6 & 6.2 & 45.2 & 1.2 & 110.6 \\
Kızarmı̧ tam buğday ekmeği & 26.9 & 1.7 & 11.0 & 8.5 & 50.4 & 1.5 & 99.2 \\
\hline
\end{tabular}


olan tam buğday ekmeği ve ısıl işleme maruz kalan tam buğday ekmeği numunelerinin, nem, yağ, protein, posa ve kül analizleri "Gözlem Gıda Kontrol ve Araştırma Laboratuvarları”nda yapılmış ve analiz edilen besinlerin $50 \mathrm{~g}$ sindirilebilir karbonhidrat içerecek şekilde verilmesi gereken ekmek miktarları hesaplanmıştır. Buna göre 50 gram sindirilebilir karbonhidrat içeren beyaz ekmeğin miktarı 91.4 g, tam buğday ekmeğin miktarı 110.6 g, kızarmış tam buğday ekmeğin miktarı 99.2 g'dır. Tablo 1'de referans besin olarak kullanılan beyaz ekmek ve test besin olarak kullanılan tam buğday ekmeği ile kızarmış tam buğday ekmeğinin besin ögesi içeriği verilmiştir.

Testten bir gün önce gönüllülere öğün planı yapılarak aşırı miktarda yemek tüketimi önlenmiş, alkol ve kafein alımları ise tamamen diyetlerinden çıkarılarak aşırı egzersizden uzak durmaları sağlanmıştır. Testin yapılmasından bir gece önce katılımcllar alışageldikleri akşam yemeğini yedikten sonra bir gece boyunca 10-12 saat aç kalarak, ertesi sabah araştırma merkezine aç durumda gelmişlerdir.

Çalışmanın ikinci aşamasında 10 gönüllü katılımcıya birer hafta arayla 8 saat açlık sonrası 50 gram glukoz içeren içecek (glikosol 50 gram), 50 gram sindirilebilir karbonhidrat içeren beyaz ekmek, 50 gram sindirilebilir karbonhidrat içeren tam buğday ekmeği ve 50 gram sindirilebilir karbonhidrat içeren, önceden $220^{\circ} \mathrm{C}$ 'de isıtılmış firında 6 dk kapağı kapalı şekilde bekletilen tam buğday ekmeği tükettirilmiştir. Glikosol hazır glukoz içeceğidir ve $200 \mathrm{~mL}$ su içermektedir. $\mathrm{Bu}$ nedenle test besinlerin tüketimi sırasında da 2 saat boyunca katılımcıların $200 \mathrm{~mL}$ su tüketmeleri sağlanmıştır. Beyaz ekmek, tam buğday ekmeği ve ısıl işleme maruz bırakılan tam buğday ekmeğinin 50 gram sindirilebilir karbonhidrat içeren test porsiyonları (sirasıyla 91.4 g, 110.6 g, 99.2 g) bir gün önce tartılarak hava geçirmeyecek şekilde streç film ile kapatılıp bir gece muhafaza edilmiştir.

Bireylerin referans besin olan 50 gram saf glukoz, beyaz ekmek ile test ekmek olan tam buğday ekmeği ve ısıl işleme maruz bırakılan tam buğday ekmeğini tüketmeden önce 0 . dk ve ilk lokmadan 15. dk, 30 . $d k, 45 . d k, 60 . d k, 90 . d k$ ve 120 . dk sonra venöz veya kapiller kan glukoz ölçümleri yapılmıştır. Bu değerler zamana karşı kan glukoz düzeyinin işaretlendiği grafik olarak çizilmiş ve glisemik eğri elde edilmiştir. Glisemik indeks değerlerinin saptanmasında "eğri altında kalan alan” yöntemi kullanılmıştır (21). Kan glukoz ölçümünün standardizasyonu için her gönüllü katılımcının parmak ucu kanı Accu-Chek Performa Nano kan glukoz ölçüm cihazı, stripleri ve parmağı delmek için Accu-Chek Softclick parmak delicisi kullanılmıştır.

\section{BULGULAR}

Araştırmaya katılan bireylerin yaş ortalamaları $22.5 \pm 3.4$ yll, BKİ ise ortalama $22.9 \pm 3.0 \mathrm{~kg} / \mathrm{m}^{2}$ ' $\operatorname{dir}$ (Tablo 2).

Tablo 2. Bireylerin yaş ve antropometrik ölçümlerine ilişkin bulgularının ortalama ve standart sapma değerleri

\begin{tabular}{lcccc}
\hline $\begin{array}{l}\text { Bireylere } \\
\text { ilişkin }\end{array}$ & $\begin{array}{c}\text { Erkek } \\
(\mathbf{n}=\mathbf{4})\end{array}$ & $\begin{array}{c}\text { Kadın } \\
(\mathbf{n}=\mathbf{6})\end{array}$ & $\begin{array}{c}\text { Toplam } \\
(\mathbf{n}=\mathbf{1 0})\end{array}$ & $\mathbf{p}$ \\
özellikler & $\overline{\mathrm{X}} \pm \mathbf{S}$ & $\overline{\mathrm{X}} \pm \mathbf{S}$ & $\overline{\mathrm{X}} \pm \mathbf{S}$ & \\
\hline Yaş (yll) & $21.5 \pm 1.0$ & $23.1 \pm 4.3$ & $22.5 \pm 3.4$ & 0.547 \\
Boy (cm) & $174.7 \pm 3.7$ & $165.1 \pm 6.4$ & $169.0 \pm 7.2$ & 0.032 \\
Ağırllk $(\mathrm{kg})$ & $71.3 \pm 7.4$ & $62.9 \pm 13.3$ & $66.3 \pm 11.6$ & 0.136 \\
BKİ $\left(\mathrm{kg} / \mathrm{m}^{2}\right)$ & $23.3 \pm 2.6$ & $22.7 \pm 3.5$ & $22.9 \pm 3.0$ & 0.670 \\
\hline
\end{tabular}

Tablo 3'te bireylerin glukoz, beyaz ekmek, tam buğday ekmeği ve kızartılmış tam buğday ekmeği tüketimi sonrasında farklı zamanlarda alınan kan glukoz miktarları yer almaktadır. Glukoz tüketimi sonrasında en düşük kan glukoz miktarı 120. dakikada $(88.8 \pm 15.70 \mathrm{mg} / \mathrm{dL})$ iken, en yüksek kan glukoz miktarı 30. dakikadadır $(149.6 \pm 20.9 \mathrm{mg} / \mathrm{dL})$. Beyaz ekmek sonrasında en düşük kan glukoz miktarı 0. dakikada $(87.0 \pm 4.8 \mathrm{mg} / \mathrm{dL})$ iken, en yüksek kan glukoz miktarı 45 . dakikadadır (130.2 $\pm 13.1 \mathrm{mg} / \mathrm{dL})$. Tam buğday ekmeği sonrasında en düşük kan glukoz miktarı 0. dakikada $(88.0 \pm 5.6 \mathrm{mg} / \mathrm{dL})$ iken, en yüksek kan glukoz miktarı 45. dakikadadır $(122.0 \pm 20.3 \mathrm{mg} / \mathrm{dL})$. Kızartılmış tam buğday ekmeği sonrasında en düşük kan glukoz miktarı 0. dakikada $(89.0 \pm 5.5 \mathrm{mg} / \mathrm{dL})$ iken, en yüksek kan glukoz miktarı 45. dakikadadır $(141.1 \pm 17.0 \mathrm{mg} /$ $\mathrm{dL})$. 
Tablo 3. Referans ve test besinlerin tüketimi sonrası kan glukoz miktarı (mg/dL)

\begin{tabular}{|c|c|c|c|c|}
\hline 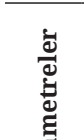 & Glukoz & Beyaz ekmek & $\begin{array}{c}\text { Tam buğday } \\
\text { ekmeği }\end{array}$ & $\begin{array}{c}\text { Kızartılmış } \\
\text { tam buğday } \\
\text { ekmeği }\end{array}$ \\
\hline 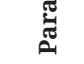 & $\overline{\mathrm{X}}_{ \pm S}$ & $\overline{\mathrm{X}}_{ \pm S}$ & $\overline{\mathrm{X}}_{ \pm} \mathrm{S}$ & $\overline{\mathrm{X}}_{ \pm \mathrm{S}}$ \\
\hline $0 . \mathrm{dk}$ & $90.80 \pm 3.36$ & $87.00 \pm 4.83$ & $88.00 \pm 5.56$ & $89.00 \pm 5.52$ \\
\hline 15.dk & $140.70 \pm 19.19$ & $95.40 \pm 8.87$ & $95.90 \pm 6.69$ & 94.90 \\
\hline 30.dk & $149.60 \pm 20.93$ & $113.20 \pm 13.31$ & $112.90 \pm 11.10$ & $118.60 \pm 12.35$ \\
\hline 45.dk & $137.90 \pm 26.04$ & $130.20 \pm 13.06$ & $122.00 \pm 20.33$ & $141.10 \pm 17.02$ \\
\hline $60 . \mathrm{dk}$ & $116.90 \pm 14.67$ & $121.40 \pm 21.62$ & $121.10 \pm 28.38$ & $130.90 \pm 20.47$ \\
\hline 90.dk & $103.40 \pm 16.37$ & $105.00 \pm 17.79$ & $110.00 \pm 13.60$ & $115.20 \pm 18.45$ \\
\hline $120 . \mathrm{dk}$ & $88.80 \pm 15.70$ & $99.60 \pm 16.47$ & $99.20 \pm 12.94$ & $116.10 \pm 17.27$ \\
\hline
\end{tabular}

Tablo 4'te tam buğday ekmeği ve ısıl işlem uygulanmış tam buğday ekmeğinin tüketimi sonrasında zamana göre kan glukoz miktarındaki değişim yer almaktadır. Yapılan analiz sonucunda tam buğday ve ısıl işlem uygulanmış olan tam buğday ekmeği alan bireylerin 0., 15., 30., 60. ve 90. dakikalarda kan glukoz miktarlarının değişmediği belirlenmiştir ( $p>0.05)$. Kan glukoz düzeylerinde 45 . dakikada ve 120. dakikada anlamlı farklılık gözlenmektedir ( $\mathrm{p}<0.05)$. Tam buğday ekmeği tüketimi sonrası 45. ve 120. dakikalardaki kan glukoz miktarı, ısıl işlem uygulanmış tam buğday ekmeğine göre daha düşük düzeydedir.

Tablo 4. Tam buğday ve ısıl işlem uygulanmış tam buğday ekmeğinin zamana göre kan glukoz düzeyleri

\begin{tabular}{llcc}
\hline & Değişkenler & $\overline{\mathrm{X}}_{ \pm} \mathbf{S}(\mathbf{m g} / \mathbf{d L})$ & $\begin{array}{c}\mathbf{p} \\
\text { değeri }\end{array}$ \\
\hline 0.dk & Tam buğday ekmeği & $88.00 \pm 5.56$ & 0.65 \\
& Kuzarmış tam buğday ekmeği & $89.00 \pm 5.52$ & \\
15.dk & Tam buğday ekmeği & $95.90 \pm 6.69$ & 0.72 \\
& Kuzarmış tam buğday ekmeği & $94.90 \pm 4.82$ & \\
30.dk & Tam buğday ekmeği & $112.90 \pm 11.10$ & 0.18 \\
& Kuzarmı̧ tam buğday ekmeği & $118.60 \pm 12.35$ & \\
45. dk & Tam buğday ekmeği & $122.00 \pm 20.33$ & 0.05 \\
& Kuzarmış tam buğday ekmeği & $141.10 \pm 17.02$ & \\
60. dk & Tam buğday ekmeği & $121.10 \pm 28.38$ & 0.31 \\
& Kuzarmş tam buğday ekmeği & $130.90 \pm 20.47$ & \\
90. dk & Tam buğday ekmeği & $110.00 \pm 13.60$ & 0.31 \\
& Kuzarmış tam buğday ekmeği & $115.20 \pm 18.45$ & \\
120. dk Tam buğday ekmeği & $99.20 \pm 12.94$ & $0.02 *$ \\
& Kuzarmış tam buğday ekmeği & $116.10 \pm 17.27$ & \\
\hline${ }^{*} p<0.05$ & & &
\end{tabular}

Referans besin olan glukoza göre test besinlerin glisemik indeks değerleri, beyaz ekmek için 81.2, tam buğday ekmeği için 78.4 ve kızarmış tam buğday ekmeği için 107.7 bulunmuştur. Bir diğer referans besin olan beyaz ekmeğe göre değerlendirildiğinde ise tam buğday ekmeğinin glisemik indeksi 96.4, kızarmış tam buğday ekmeğinin ise 132.6'dır. Çalışmada beyaz ekmeğe göre hesaplanan glisemik indeks değerleri, glukoza göre hesaplanan glisemik indeks değerlerinden yaklaşık olarak 1.2 kat daha yüksek çıkmıştır.

\section{TARTIŞMA}

Türkiye'de ekmek ve tahıl ürünleri en fazla tüketimi olan besin grubudur. Türkiye Beslenme ve Sağlık Araştırması 1974 araştırma sonuçlarına göre günlük enerjialımının \%58'iekmekve diğer tahılürünlerinden sağlanırken, \%44'ü sadece ekmekten sağlanmaktadır. Türkiye Beslenme ve Sağlık Araştırması 2010'da tam tahıl ekmeklerinin tüketim sıklığı, beyaz ekmek tüketimine kıyasla düşüktür. TBSA 2010 sonuçlarına göre bireylerin \%71.4’ü tam tahıllı ekmek türlerini hiç tüketmemektedir (22).

Besinler üzerine uygulanan hazırlama ve pişirme teknikleri kan glukoz düzeyini ve insülin yanıtını etkiler. Nişasta jelatinizasyonu, pişirme sıcaklığı, pişirme süresi ve nişasta sindirilebilirlik oranını etkileyen etmenler ekmeğin glisemik indeksini belirler (23). Uluslararası Glisemik İndeks ve Yük Tablosu'nda tam buğday ekmeğinin glisemik indeksi Avustralya'da 70, Kanada'da 52-72, Slovenya'da 63, Amerika'da 73 ve Güney Afrika'da ise 75 olarak bildirilirken Türkiye'ye ait tam buğday ekmeğinin glisemik indeksi 49 olarak ifade edilmektedir (24). Bu çalışmada tam buğday ekmeğinin glisemik indeksi 78.4 olarak saptanmıştır. $\mathrm{Bu}$ farklılığın nedeni ekmeğin yapımı sürecinde içine ilave edilen su miktarı, pişirme süresi, fermentasyon için kullanılan maya çeşidi (25), fermentasyon sürecinde çıkan organik asitlerin gastrik boşalmayı etkileyen pH'sı olabilir (26). Diğer taraftan kullanılan kan glukoz örneğinin kapiller veya venöz kan olması gibi bireysel etmenler de besinlerin glisemik indeksini değiştirebilmektedir (27).

Besinlerin içeriğindeki besin ögeleri (posa, nişastanın 
granüler yapısı, amiloz amilopektin oranı, içeriğindeki yağ miktarı) kadar, besin hazırlamada ve pişirmede uygulanan işlemler de glisemik indeksi etkilemektedir (24). Bu araştırmada firında $220^{\circ} \mathrm{C}$ sıcaklıkta 6 dakika süresince isıl işlem uygulanan tam buğday ekmeğinin glisemik indeksi 107.7 olarak bulunmuştur. Ekmeğin pişirilmesi nişastanın retrogradasyonuna, pişirilen ekmeğin tekrardan ısıtılması dekstrinizasyonuna katkıda bulunur. Ekmeğin kuru ısıya maruziyeti sonucunda nişastada bulunan amiloz ve amilopektin yapı daha küçük ünitelere parçalanarak dekstrinleri oluşturur. Dekstrinizasyon işlemi sonucu oluşan daha küçük partiküllerin sindirim ve emiliminin göreceli olarak daha hızlı olması glisemik indeksin artışına neden olur (20). Ekmeğin firında ısıl işleme maruz bırakılması sonucu glisemik indeksindeki artışın bir diğer nedeni nem kaybına bağlı olarak 100 gramdaki sindirilebilir karbonhidrat miktarındaki artıştır. Tam buğday ekmeğinin sindirilebilir karbonhidrat oranı \%45.2 iken isıl işlem görmüş tam buğday ekmeğinin nem miktarındaki azalmaya bağlı olarak bu oran \%50.4'e yükselmiştir.

Obezite, kalp damar hastalıkları, diyabet ve bazı kanser türlerinin önlenmesinde ve tedavisinde tam buğday unundan yapılan ekmeğin tüketimi ve ekmeklerde kullanılan unun randımanının arttırılmaması gerektiği bildirilmektedir (22). Tahılların ve ekmeğin çeşidi ve miktarı kadar uygulanan hazırlama ve pişirme yöntemi de sağlığı etkileyebilir. Nişastalı ürünlerin glisemik yanıtını etkileyebilen küçük farklılıkların azalan kardiyovasküler hastalık riski ve daha iyi sağlanabilen glisemik kontol gibi sağlık üzerine olumlu etkileri olabilmektedir (28). Bu araştırmanın sonucuna göre firında 6 dakika süresince $220^{\circ} \mathrm{C}$ isıya maruz kalan ekmeğin glisemik indeksinde \%27 artış saptanmıştır. Isıl işlemin glisemik indeksi arttırmasından dolayl, ekmek ile ilgili önerilerde ekmeğin ısıl işleme maruz bırakılmadan tüketiminin önemi anlatılmalıdır.

$\mathrm{Bu}$ çalışmanın birkaç sınırlılığı bulunmaktadır. Araştırmanın birinci sınırlılığı araştırmaya katılan bireylerin kan glukoz ölçümlerinin duplike yapılmamasıdır. Bu çalışmanın bir diğer sınırlılığı olan GI çalışmalarında randomizasyon yapılması gerekliliğinin sağlanamamasıdır.

Çıkar çatışması - Conflict of interest: Yazarlar çıkar çatışması olmadığını beyan ederler. - The authors declare that they have no conflict of interest.

\section{KAYNAKLAR}

1. Venn BJ, Green TJ. Glycemic index and glycemic load: measurement issues and their effect on diet-disease relationships. Eur J Clin Nutr 2007;61 (Suppl 1):S122-131.

2. World Health Organization, Carbohydrates in Human Nutrition. Report of a Joint FAO/WHO Expert Consultation. (Chapter 4); 1997 Apr 14-18; Italy, Rome.

3. Jenkins DJ, Wolever TM, Taylor RH, Barker H, Fielden $\mathrm{H}$, Baldwin JM, et al. Glycemic index of foods: a physiological basis for carbohydrate exchange. Am J Clin Nutr 1981;34(3):362-366.

4. Sacks FM, Carey VJ, Anderson CA, Miller ER 3rd, Copeland T, Charleston J, et al. Effects of high vs low glycemic index of dietary carbohydrate on cardiovascular disease risk factors and insulin sensitivity: the OmniCarb randomized clinical trial. JAMA 2014;312(23):2531-2541.

5. Wang ML, Gellar L, Nathanson BH, Pbert L, Ma Y, Ockene I, et al. Decrease in glycemic index associated with improved glycemic control among Latinos with type 2 diabetes. J Acad Nutr Diet 2015;115(6):898-906.

6. Ha V, Viguiliouk E, Kendall CWC, Balachandran B, Jenkins DJA, Kavsak PA, et al. Effect of a low glycemic index diet versus a high-cereal fiber diet on markers of subclinical cardiac injury in healthy individuals with type 2 diabetes mellitus: An exploratory analysis of a randomized dietary trial. Clin Biochem 2017;50(18):1104-1109.

7. Gutschall MD, Miller CK, Mitchell DC, Lawrence FR. A randomized behavioural trial targeting glycaemic index improves dietary, weight and metabolic outcomes in patients with type 2 diabetes. Public Health Nutr 2009;12(10):1846-1854.

8. Esposito K, Maiorino MI, Di Palo C, Giugliano D; Campanian Post-Prandial Hyperglycemia Study Group. Dietary glycemic index and glycemic load are associated with metabolic control in type 2 diabetes: The CAPRI experience. Metab Syndr Relat Disord 2010;8(3):255-261.

9. Türk Gıda Kodeksi. Ekmek ve Ekmek Çeşitleri Tebliği; (Tebliğ No: 2012/2).

10. TBSA. “Türkiye Beslenme ve Sağllk Araştırması 2010: Beslenme Durumu ve Alışkanllklarının Değerlendirilmesi Sonuç Raporu.” Sağlık Bakanlığı Sağlık Araştırmaları Genel Müdürlüğü, Hacettepe Üniversitesi Sağlık Bilimleri Fakültesi Beslenme ve Diyetetik Bölümü, Ankara Numune Eğitim ve Araştırma Hastanesi. Ankara: Sağlık Bakanlığı Yayın No: 931. 2014. 
11. Visek J, Lacigova S, Cechurova D, Rusavy Z. Comparison of a low-glycemic index vs standard diabetic diet. Biomed Pap Med Fac Univ Palacky Olomouc Czech Repub 2014;158(1):112-116.

12. Liu S, Manson JE, Stampfer MJ, Holmes MD, Hu FB, Hankinson SE, et al. Dietary glycemic load assessed by food-frequency questionnaire in relation to plasma high-density-lipoprotein cholesterol and fasting plasma triacylglycerols in postmenopausal women. Am J Clin Nutr 2001;73(3):560-566.

13. Ahmed M, Gannon MC, Nuttall FQ. Postprandial plasma glucose, insulin, glucagon and triglyceride responses to a standard diet in normal subjects. Diabetologia 1976;12(1):61-67.

14. Bhupathiraju SN, Tobias DK, Malik VS, Pan A, Hruby A, Manson JE, et al. Glycemic index, glycemic load, and risk of type 2 diabetes: results from 3 large US cohorts and an updated meta-analysis. Am J Clin Nutr 2014;100(1):218232.

15. Hu FB, Manson JE, Stampfer MJ, Colditz G, Liu S, Solomon CG, et al. Diet, lifestyle, and the risk of type 2 diabetes mellitus in women. N Engl J Med 2001;345(11):790-797.

16. Salmeron J, Ascherio A, Rimm EB, Colditz GA, Spiegelman D, Jenkins DJ, et al. Dietary fiber, glycemic load, and risk of NIDDM in men. Diabetes Care 1997;20(4):545-550.

17. Meyer KA, Kushi LH, Jacobs DR Jr, Slavin J, Sellers TA, Folsom AR. Carbohydrates, dietary fiber, and incident type 2 diabetes in older women. Am J Clin Nutr 2000;71(4):921-930.

18. Øverby NC., Sonestedt E., Laaksonen D E., Birgisdottir BE. (2013). Dietary fiber and the glycemic index: a background paper for the Nordic Nutrition Recommendations 2012. Food Nutr Res, 57(1), 20709.

19. Burton P, Lightowler HJ. The impact of freezing and toasting on the glycemic response of white bread. Eur J
Clin Nutr 2008;62(5):594-599.

20. Brown A. Understanding Food: Principles and Preparation. 5th ed. Cengage; 2014. 374 p.

21. Wolever TM, Jenkins DJ, Jenkins AL, Josse RG. The glycemic index: methodology and clinical implications. Am J Clin Nutr 1991;54(5):846-854.

22. TC Sağlık Bakanlığı ve Sağlık Hizmetleri Genel Müdürlüğü. "Türkiye Sağlıklı Beslenme ve Hareketli Hayat Programı (2010-2014)." Kuban Matbaacılık Yayıncılık, Ankara, 2010.

23. Rizkalla SW, Laromiguiere M, Champ M, Bruzzo F, Boillot J, Slama G. Effect of baking process on postprandial metabolic consequences: Randomized trials in normal and type 2 diabetes subjects. Eur J Clin Nutr 2007;61(2):175-183.

24. Ludwig DS. Dietary glycemic index and obesity. J Nutr 2000;130(2S Suppl):280S-283S.

25. Najjar AM, Parsons PM, Duncan AM, Robinson LE, Yada RY, Graham TE. The acute impact of ingestion of breads of varying composition on blood glucose, insülin and incretins following first and second meals. Br J Nutr 2009;101(3):391-398.

26. Liljeberg HG, Lönner CH, Björck IM. Sourdough fermentation or addition of organic acids or corresponding salts to bread improves nutritional properties of starch in healthy humans. J Nutr 1995;125(6):1503-1511.

27. Wolever TM, Jenkins DJ, Vuksan V, Josse RG, Wong GS, Jenkins AL. Glycemic index of foods in individual subjects. Diabetes Care 1990;13(2):126-132.

28. Brand-Miller J, Hayne S, Petocz P, Colagiuri S. Lowglycemic index diets in the management of diabetes: a meta-analysis of randomized controlled trials. Diabetes Care 2003;26(8):2261-2267. 